METAgraphias: letra I de intervençãoPERFORMANCEinstalação v.3 n.2 junhol2018

esperma sobre tela • Caio linkings (caiojinkings@hotmail.com)

\title{
esperma sobre tela
}

\author{
Caio Jinkings
}




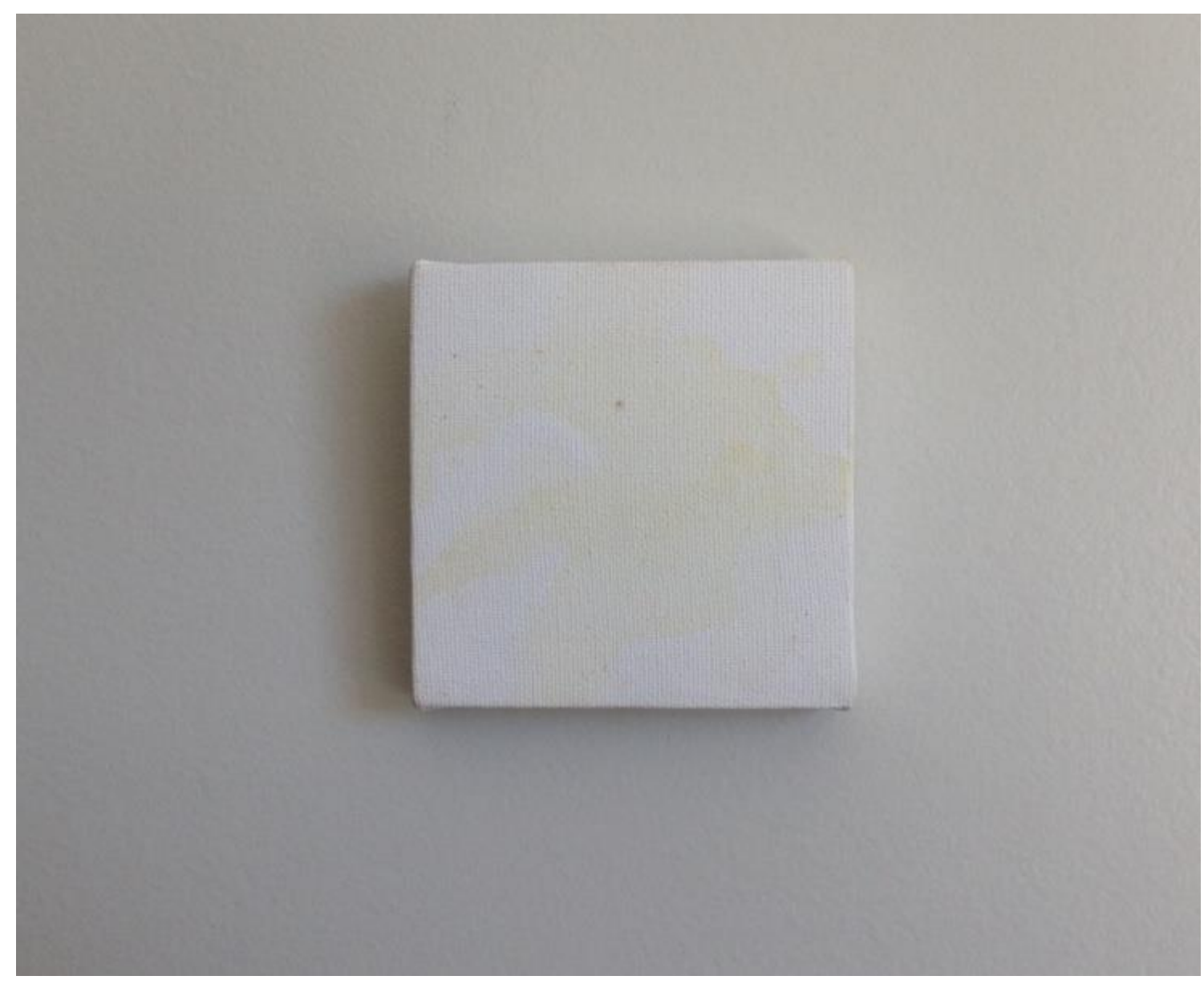

Esperma sobre tela

$10 \times 10$

"(...) em determinadas circunstâncias qualquer um pode ser parte de uma obra de arte. "

\section{Walter Benjamin}

"Gozo grosso pensando: sou um escritor brasileiro. Coisa de macho."

Cartas de um sedutor, Hilda Hilst 
"Se você não tiver coração, as mãos falarão por você. "

Breviário sobre o corpo, Lygia Clark

O processo criativo deste trabalho se deu a partir de compreender a reprodutibilidade citada em Walter Benjamin, no seu ensaio "A obra de arte na era de sua reprodutibilidade técnica", não somente em seu contexto mecânico, mas também biológico: o encontro do esperma com o óvulo, a gênese do artista. Para traduzir essa ideia, usei de dois víeis: o esperma masculino e a tela. Esta como suporte, surgiu a partir de uma pulsante vontade de reestruturação de signos e de subverter a aura por trás de um objeto tão consagrado e iconológico dentro da 
história da arte.

Busquei referência em Lygia Clark, principalmente em seus trabalhos "Memória do Corpo" e "Bicho", onde ela propõe uma reestruturação simbólica de objetos através da memória e seu contato sensorial; e, também, na sua proposta de arte participativa onde o corpo do artista some e é substituído pelo corpo do espectador.

Figura 1 e 2: "Memória do corpo", Lygia Clark
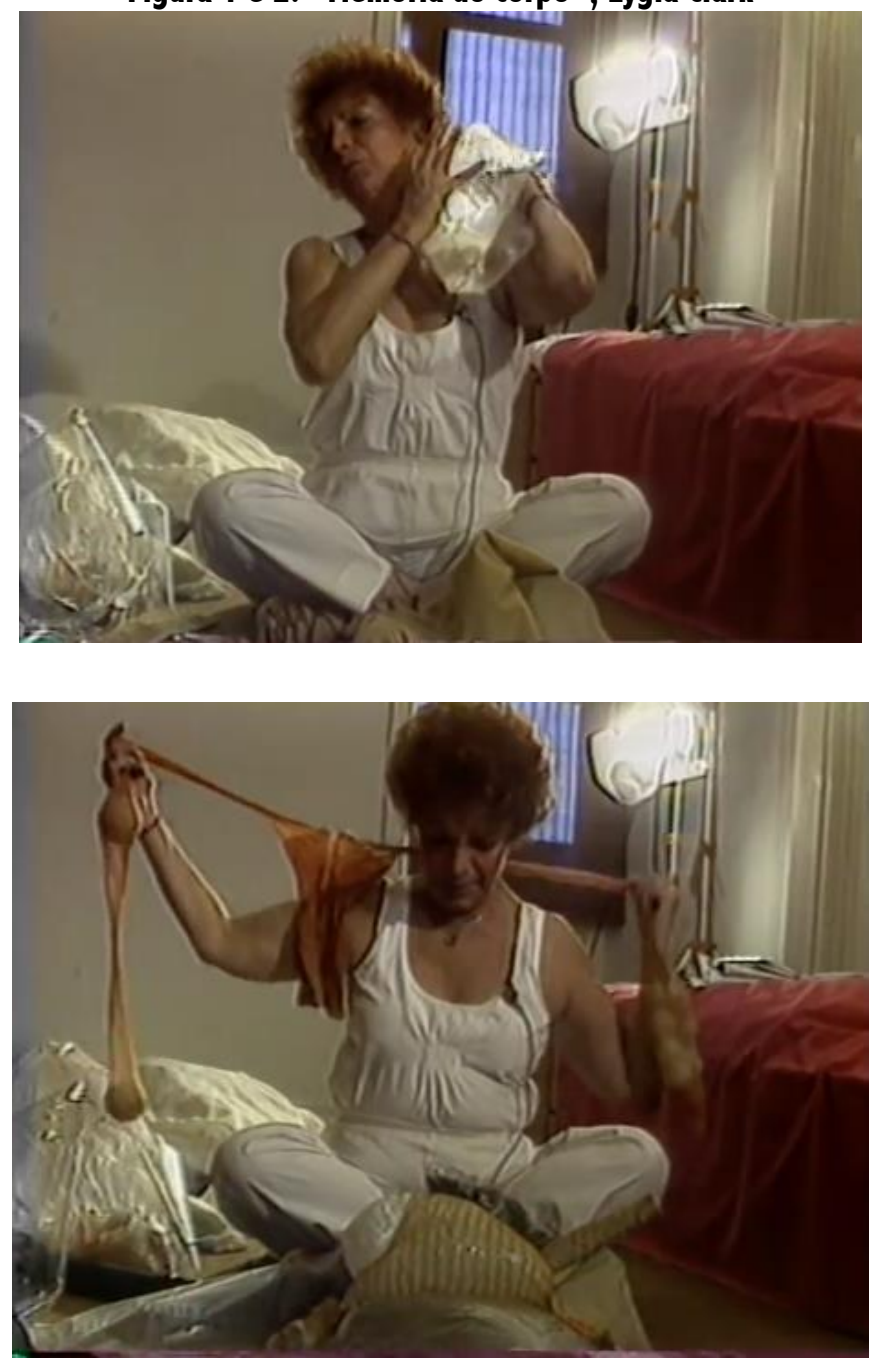

Fonte: https://www.youtube.com/watch?v=9ymjW6yVKAg\&t 
O aplicativo Grindr, tradicionalmente usado para marcar encontros entre homens do mesmo sexo, foi usado como plataforma de encontro entre mim e os participantes do trabalho. Foi criado um perfil onde foi especificado a proposta do projeto e o convite aberto para os interessados em participar - uma vez que explicadas as diretrizes do trabalho, eu me dirigia com a tela até a residência do participante e aguardava a realização do ato de masturbação.

\section{Figuras 3 a 6: prints do aplicativo Grindr}

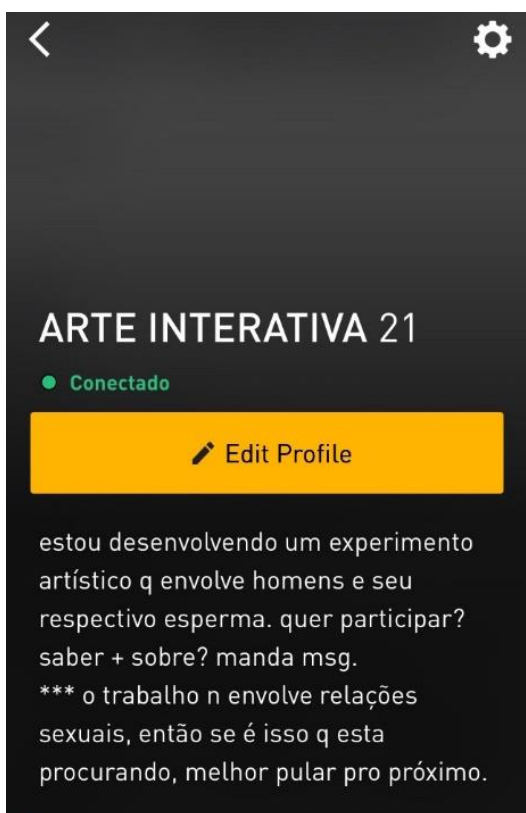

Clash Royale

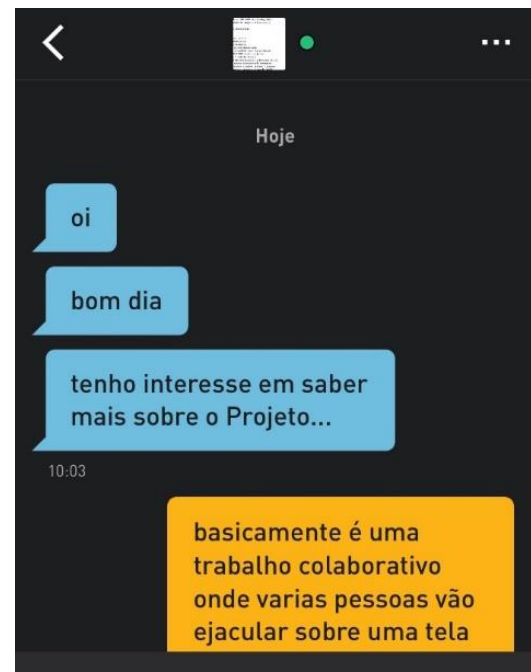

Diga algo .

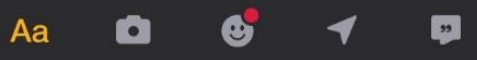

MORE GUYS, MORE FILIERS

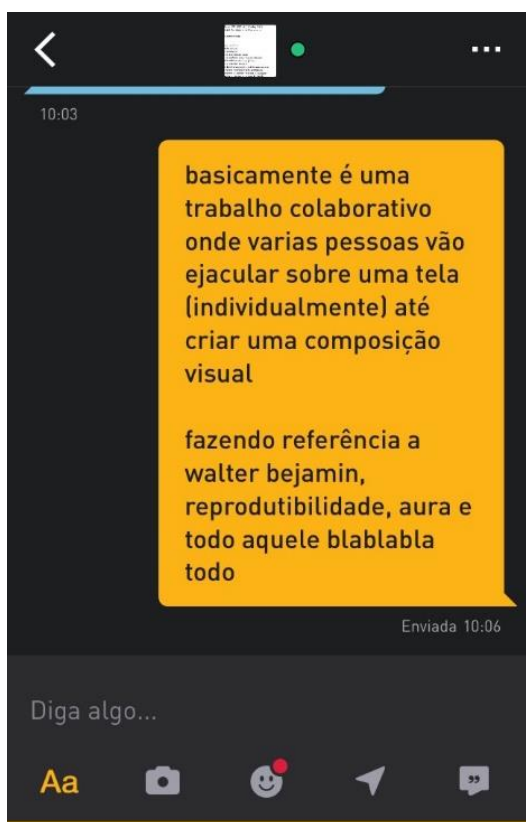

TRY ONE WEER FREE 


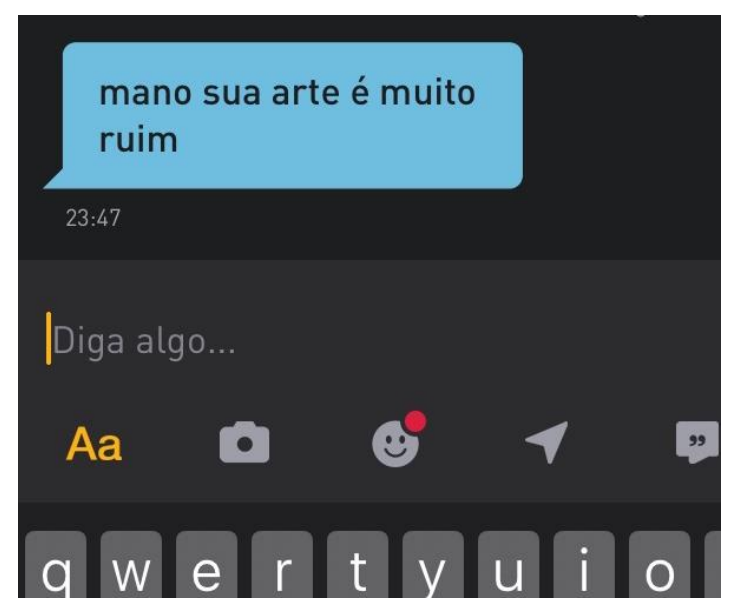

É importante ressaltar que em nenhum momento acompanhei ou participei junto a outra pessoa, sendo a minha proposta inicial do trabalho de atuar como um autor, não como produtor.

Durante essa fase do trabalho foi interessante analisar o grande interesse do público em participar do projeto (algo que não esperava) e o entusiasmo de estar dentro de um contexto artístico de alguma forma, principalmente como produtor direto de uma suposta "obra de arte". Perguntas como "isso será exposto em algum museu? "; "eu serei creditado no trabalho? "; "existe cachê? "; foram recorrentes durante esse processo.

Isso traz à tona uma reflexão acerca o conceito de aura proposto por Benjamin, o qual o centraliza no aspecto material da obra de arte e não necessariamente à figura social do artista em si. Fazendo um breve parâmetro histórico, a progressão da visibilidade social que o artista adquiriu do Renascimento até a contemporaneidade é notória e relevante ao se falar sobre aura artística. Basquiat, ao desfilar em 1987 na coleção primavera/verão da marca Comme des Garçons, sob convite de Rei Kawakubo, deixava uma mensagem ao mundo: o artista é a nova musa e sex symbol. 
Figuras 7 e 8: Jean Michel Basquiat em desfile da Comme des Garçons
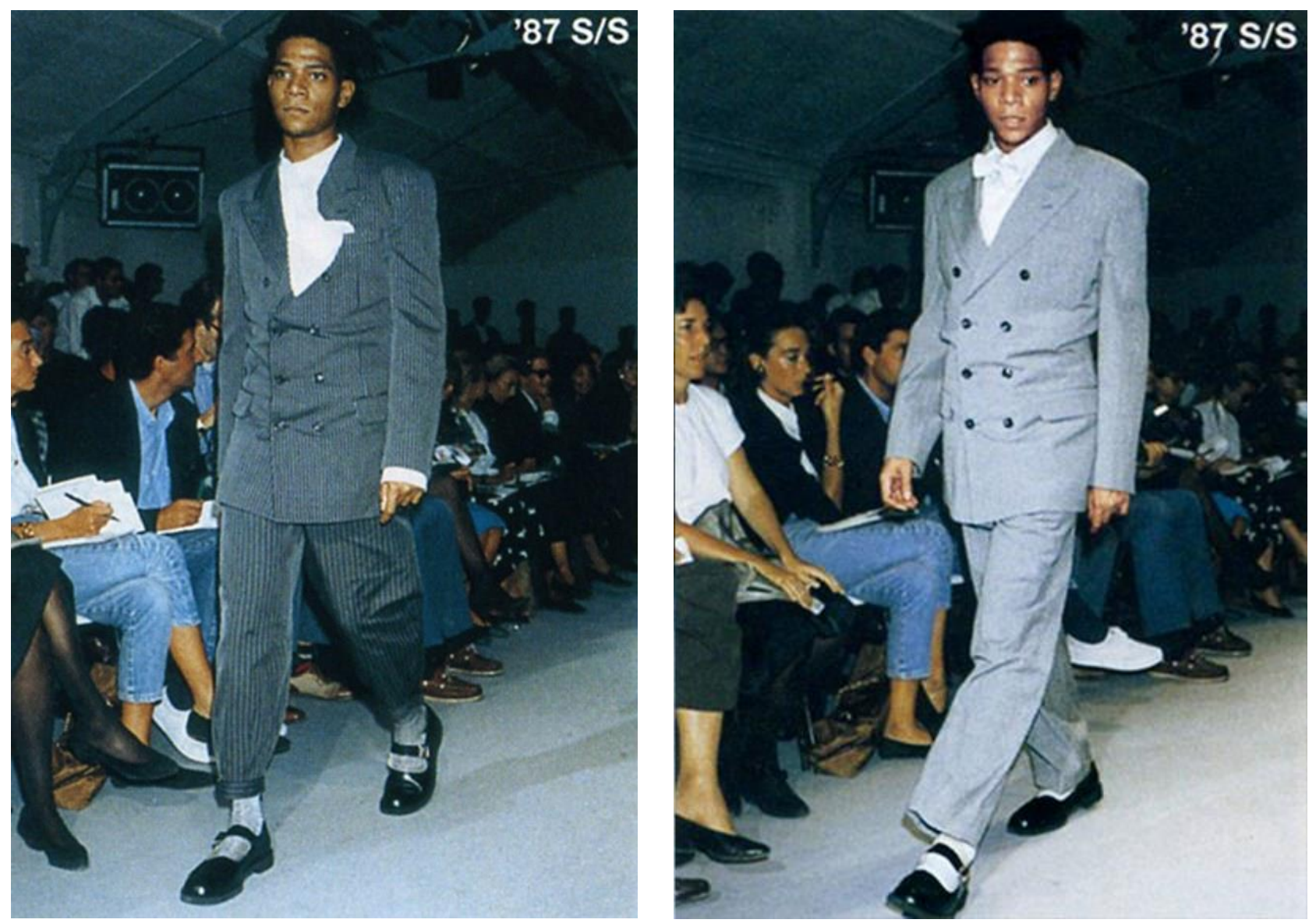

Fonte: https://www.gq.com/story/jean-michel-basquiat-style-inspiration

Apesar da obra final se concretizar na tela manchada, acredito que o trabalho migra mais para uma arte conceitual que pitoresca. Apesar disso, partindo de uma perspectiva poética, o ato mecânico de manusear um pincel com pigmento no seu topo sobre uma tela se assemelha, simbolicamente, ao ato de manusear um pênis com esperma no seu topo também sobre uma tela. Pintura não passa de uma mancha, mas ainda assim aquela mancha quer dizer tudo. 
METAgraphias: letra I de intervençãoPERFORMANCEinstalação v.3 n.2 junhol2018

esperma sobre tela • Caio linkings (caiojinkings@hotmail.com)

Agradecimentos a Gato nerd, SARRO AT AN, sem histórico e Pass c/ local.

\section{REFERÊNCIAS BIBLIOGRAFIAS}

BENJAMIN, Walter. A obra de arte na era de sua reprodutibilidade técnica. São Paulo: L\&PM, 2013.

CLARK, Lygia. Breviário sobre o corpo.

ISSN 2448-1246 
METAgraphias: letra I de intervençãoPERFORMANCEinstalação v.3 n.2 junhol2018

esperma sobre tela • Caio Jinkings (caiojinkings@hotmail.com)

HILST, Hilda. Cartas de um sedutor. São Paulo: Globo Editora, 2002. 